\title{
Retrospective study describing the mode of hand injuries in Eastern Nepal
}

\author{
S Bajracharya, P Kumar, BP Shrestha \\ Department of Orthopaedics, B.P. Koirala Institute of Health Sciences, Dharan, Nepal
}

\begin{abstract}
Background: This retrospective review was performed to identify the incidence, causes, and details of hand injuries in patients presenting to a tertiary hospital in Eastern Nepal. Objective: To identify the incidence, causes, and details of hand injuries in patients. Method: Records of all patients who had sustained hand injuries for last 5 years were collected from the medical record section. Altogether 832 injuries of hand in 484 patients were reported in this review. These patients were reviewed for age at the time of injury, gender, location of the incident, mechanism of injury, and fracture specifies. Result: 414 (85.5\%) males with mean age of $28.79 \pm 12.81$ and in female with $30.43 \pm 17.13$ yrs were found. Machinery injuries $(25.2 \%)$ were the most common causes of injuries followed by RTA (14.5\%). Metacarpal bone fractures $(34.6 \%)$ were the commonest injury of the hand. Most of the patients were treated with open reduction and fixation with $\mathrm{K}$ wires. Conclusion: The study reveals the aetio-epidemiological and clinical aspect of hand injuries with its alarming burden in Nepal.
\end{abstract}

Key words: Hand injuries, retrospective study, treatment modalities

\section{Introduction}

Intricate in design and function, the hand is an amazing work of anatomy. Form follows function in the hand; therefore, any injury to the underlying structures of the hand carries the potential for serious handicap. To reduce this risk, even the smallest hand injuries require a good medical evaluation. The goal with injuries to the hand is a rapid and

\section{Address for correspondence}

Dr. Suraj Bajracharya

Associate Professor

Department of Orthopaedics

KIST Medical College, Tribhuvan University, Nepal

E-mail: drsurajbajra@yahoo.com accurate initial evaluation. In other words, once an injury occurs, the doctor strives to begin medical treatment quickly so the shortand long-term effects can be minimized. The hand consists of 27 bones when the 8 bones of the wrist are included. When the other associated structures (nerves, arteries, veins, muscles, tendons, ligaments, and joint cartilage) are considered, the potential for a variety of injuries exists when trauma involves the hand. Hand injuries account for nearly $10 \%$ of hospital emergency department visits. 
A recent series of 1,000 consecutive hand injuries showed the following distribution: $42 \%$ lacerations (cuts), 27\% contusions (bruises), 17\% fractures (broken bones), and $5 \%$ infections. The most common cause of the injuries was blunt trauma (50\%) followed by injury from a sharp object (25\%). Hand injuries can be divided into 5 general categories: (1) lacerations (cuts), (2) fractures and dislocations, (3) soft tissue injuries and amputations, (4) infections, and (5) burns.

\section{Methods}

A retrospective survey of the medical charts of all patients attending department of the orthopaedics via emergency room and/or OPD of B.P. Koirala Institute of Health Sciences, Dharan, Nepal was done from January $1^{\text {st }}, 2000$ to December $31^{\text {st }}, 2005$ was performed. Study included injuries to phalanges, metacarpals, carpal bones along with injuries to tendons distal to the wrist joint. Both open and closed fractures and dislocation of hand bone and joints were included. Pure tendon cuts were excluded from the study, but fractures or fracture/dislocations associated with tendon injuries were included. Only patients from the Eastern region of Nepal were included. Age, sex, occupation, time since injury, cause of injury, pattern of injury, diagnosis and treatment given were noted in the preformed proforma.

\section{Results}

The patients consist of 70 (14.5\%) females and $414(85.5 \%)$ males, with a mean age of $30.43 \pm 17.13$ years in females and $28.79 \pm$ 12.81 years in males. There was right sided preponderance than left sided hand fractures as shown in Table 1.

Table 1: Patients' characteristics

\begin{tabular}{|cc|c|}
\hline \multicolumn{2}{|c|}{ Characteristics } & \multicolumn{1}{|c|}{ Numbers (\%) } \\
\hline Sex & Male & $414(85.5 \%)$ \\
& Female & $70(14.5 \%)$ \\
\hline Age & & \\
& Male & $28.79 \pm 12.81 \mathrm{yrs}$ \\
& Female & $30.43 \pm 17.13 \mathrm{yrs}$ \\
\hline $\begin{array}{c}\text { Sidedness: } \\
\text { Right } \\
\text { Left }\end{array}$ & $292(60.3 \%)$ \\
& $190(39.3 \%)$ \\
\hline
\end{tabular}

Machinery injuries (25.2\%) were the most common causes of injuries followed by RTA (14.5\%) and Physical assault by Khukuri (14.5\%). Khururi, a special type of knife or weapon of Nepal, is used by Gurkhas in different war time, due to which they are popular in the world history as Gurkhas. The other causes of injuries are shown in Table 2. 
Table 2: Etiology of hand injuries

\begin{tabular}{|l|c|c|}
\hline \multicolumn{1}{|c|}{ Major five causes } & No. of patients & Percentage \\
\hline 1. Machinery injury & 122 & $25.2 \%$ \\
2. Physical assault by khukuri & 70 & $14.5 \%$ \\
3. Road traffic accident & 70 & $14.5 \%$ \\
4. Accidental sharp cut injury & 68 & $14 \%$ \\
5. Playground injury & 40 & $8.3 \%$ \\
6. Others & 114 & $23.55 \%$ \\
\hline & 484 & $100 \%$ \\
\hline
\end{tabular}

Metacarpal bone fractures (48\%) followed by proximal phalanges $(23.5 \%)$ were commonest injury occurred in hand injuries.
The site and number of fractures of hand bones is elaborately shown in table 3 .

Table 3: Site of fractures in hand

\begin{tabular}{|l|c|c|}
\hline Site of fractures & No. of fractures & Percentage (\%) \\
\hline 1. Metacarpals & 288 & 34.6 \\
2. Proximal phalanges & 196 & 23.55 \\
3. Middle phalanges & 58 & 7.00 \\
4. Distal phalanges & 87 & 10.45 \\
5. MCP joints & 65 & 7.99 \\
6. PIP joints & 46 & 5.52 \\
7. DIP joints & 63 & 7.55 \\
8. Carpals & 29 & 3.48 \\
9. & 832 & 100 \\
\hline
\end{tabular}

Table 4 describes the fracture pattern of hand injuries. Open fractures were common as the commonest mode of hand injuries were Machinery injury followed by RTA. 
Table 4: Fracture pattern

\begin{tabular}{|c|c|c|}
\hline Descriptions & Total numbers ( in patients) & Percentage (\%) \\
\hline $\begin{array}{l}\text { 1. Closed : Open fractures / } \\
\text { dislocations }\end{array}$ & 265: 567 & $31.85: 68.14$ \\
\hline $\begin{array}{l}\text { 2. Total fractures without dislocations } \\
( \pm \text { Tendon cut })\end{array}$ & 658 & 79.08 \\
\hline $\begin{array}{l}\text { 3. Transverse/Oblique/Spiral: } \\
\text { Comminuted fracture }\end{array}$ & 528: 189 & $73.64: 26.35$ \\
\hline 4. Intra-articular extension & 147 & 17.66 \\
\hline 5. Fractures associated dislocations & 174 & 20.92 \\
\hline $\begin{array}{l}\text { 6. Fracture / Dislocations associated } \\
\text { no. of tendon injuries } \\
\text { a. Extensor tendons } \\
\text { b. Flexor tendons }\end{array}$ & $\begin{array}{l}465 \\
276 \\
189\end{array}$ & 43.87 \\
\hline 7. Pure dislocations without fractures & 115 & 13.8 \\
\hline
\end{tabular}

According to the severity of the injury, in patient department according to severity availability of time for emergency operation, and availability of the beds. Table 5 reveals and most importantly affordability of the patients for operation determined the treatment and admission of the patients with hand injuries. The admission of patients were done observation room of ER or orthopaedic the number of patients admitted in in-patient department, observation room of ER and duration of hospital day as well as the patients discharged from ER after emergency management.

Table 5: Hospital care statistics

\begin{tabular}{|l|c|c|}
\hline & No. of patients / duration & Percentage (\%) \\
\hline $\begin{array}{l}\text { Hospital admissions and stay } \\
\text { 1. Numbers of patients admitted }\end{array}$ & 188 & 38.84 \\
2. Duration of hospital stay & $2.24 \pm 0.866$ days & \\
\hline
\end{tabular}




\begin{tabular}{|l|c|c|}
\hline $\begin{array}{l}\text { Emergency care and stay at ER } \\
\text { 3. Numbers of patients kept in } \\
\text { observation room of emergency } \\
\text { department }\end{array}$ & 30.37 \\
4. Duration of patient stay in \\
observation room of emergency \\
department
\end{tabular}

Most of the patients were treated by open reduction and internal fixation at emergency operating room on the same day of injury. Thorough wound debridement was done in all cases of open hand injures. K-wires, External fixators (pins and rods, Zess fixator), screw/plates were used to fix the fractures.
For intra articular fractures, where possible, pin and rubber traction method was used, which showed good outcome in most of the cases. Except in cases with amputations and disarticulations, tendon repairs were done. Table 6 gives us overall picture of different treatment modalities opted.

Table 6: Treatment modalities

\begin{tabular}{|c|l|c|}
\hline S.N. & \multicolumn{1}{|c|}{ Treatment modalities } & No. of patients \\
\hline 1. & Wound debridement and K-wires fixation & 197 \\
2. & Open reduction internal fixation with K- wires & 355 \\
3. & Conservative treatment with B/E slab & 127 \\
4. & Conservative treatment with Buddy's strapping & 45 \\
5. & Open reduction internal fixation with screw/plates & 40 \\
6. & Wound debridement and pin and rubber traction & 26 \\
7. & Wound debridement and external fixator & 42 \\
8. & Disarticulation through joints & 43 \\
9. & Amputation of fingers & 66 \\
10. & Tendon repairs & 297 \\
\hline
\end{tabular}




\section{Discussion}

Little is known about the magnitude of hand injuries at national levels. This paper quantifies and characterizes the incidence of hand injuries that require acute medical attention at emergency departments in Eastern part of Nepal. Hand injuries show a peak for twenties of male and females result mainly from machinery injury and physical assault, the majority affects metacarpals and result mainly in superficial injuries, open wounds and fractures, a small proportion of the victims were admitted into hospital. Data recording on the backgrounds of accidents and their long term consequences should be improved. ${ }^{1}$

Angermann $P$ et.al. reports the causes, characteristics and treatment of injuries to the hand and wrist presented to five accident and emergency departments in a 2-year survey of $13 \%$ of the Danish population. The rate of injury to the hand or wrist was $28.6 \%$ of all injuries, or 3.7 per 100,000 inhabitants per year. $34 \%$ of the accidents were domestic, $35 \%$ were leisure accidents, $26 \%$ were occupational and $5 \%$ were traffic accidents. Only $2 \%$ of the patients were admitted to hospital for further treatment or observation and $13 \%$ were referred to a hospital as outpatients. The most frequent causes for admission were fractures (42\%), tendon lesions (29\%) and wounds (12\%). ${ }^{2}$
The overall incidence of self-reported occupational hand injuries in a Danish population was estimated to $4.7 \%$, with the highest incidence among the youngest, men and employees in the production and building industries. The life-time risks were $93 \%$ for men and $73 \%$ for women. Age and gender were found to be independent risk factors for the occupational hand injuries. Preventiontrials against hand injuries should therefore have a high priority, and it is recommended that hospital data files are used increasingly in future prevention programs. ${ }^{3}$

The study done by Hansen TB et al. was to investigate the incidence of hand injuries due to farming accidents in a defined population with a representative mixture of agricultural activities. During a 12-month period all agricultural accidents treated at the five hospitals in the County of Ringkobing, Denmark were prospectively registered. Follow-up was done by telephone interview 4 months after the accident. ${ }^{4}$

The survey done by Packer GJ et al. emphasizes the differences between hand injuries and injuries of other sites, identifies the risk factors for hand injuries and has implications for the management of hand injuries in a District General Hospital. ${ }^{5}$ In one of a retrospective survey of patients with fractures and dislocations attending the accident department of a District General Hospital, comparison was made between 
patients with fractures and dislocations in the hand and fractures and dislocations of other sites. Patients with hand injuries accounted for $28 \%$ of the total patients seen. They were more likely than other fracture patients to be male and between the ages of 10 and 40 years. Almost a quarter of hand injuries attended on Monday. Leisure activities outside the home formed the commonest aetiological factor. Only $66 \%$ of patients with hand injuries attended the accident department within 24 hours of injury. The little finger was the commonest site of injury. This survey emphasizes the differences between hand injuries and injuries of other sites, identifies the risk factors for hand injuries and has implications for the management of hand injuries in a District General Hospital. ${ }^{6}$

A retrospective survey of the medical charts of all 36,518 patients attending the accident and emergency department of the VU University Medical Centre, in Amsterdam, from January 1 to December 31, 1996 was performed. Of these, 4303 sustained one or more fractures, and hand fractures accounted for $19 \%$ of all fractures. Patients with hand fractures were typically men aged between 15 and 35 years. The right hand was involved as often as the left. Most of the hand fractures involved the metacarpals but, as a group of bones, the combined phalanges were most commonly fractured. The little finger ray was most commonly injured of the hand. We found no seasonal variability in the incidence of hand fractures. ${ }^{7}$

One thousand consecutive fractures of the metacarpals, phalanges, and carpal bones have been recorded over a period of about 10 months in Bergen, Norway, to find out the relative incidence of these fractures in an unselected series: this corresponds well with the few other reports of the incidence of hand fractures that we could find. ${ }^{8}$

It is shown that hand injuries are extremely usual and imply enormous costs to the community. Postgraduate training in hand surgery is therefore desirable for all those general and orthopaedic surgeons, who deal with the treatment of patients with hand injuries. ${ }^{9}$

Epidemiological data about hand injuries that affect young patients of productive age, are important to optimize resources and organization of the health care system. ${ }^{10}$

During investigation of 723 cases involving injury in the agricultural work place, Boyd $\mathrm{J}$ et al recorded 94 cases of injury to the wrist, hand or finger; $40 \%$ of these resulted in permanent impairment. Agricultural equipment caused $71 \%$ of the injuries, and animals caused $15 \%$. Amputation, fracture, laceration, and contusion were the injuries most frequently recorded, and fingers were the parts most affected. Sixty percent of the victims lost more than one week of work. The causes of the incidents varied, but our 
investigations indicated that many resulted in part from inexperience or poor work practices. The data indicate a surprising amount of work time lost for what might be regarded as a less than major injury and a need for additional attention to engineering based interventions and injury prevention. ${ }^{11}$

\section{Conclusion}

The study shows the aetio-epidemiological aspects of hand injuries with pattern and details of hand injuries. The important aspect of the study that it points out is the young patients of productive age were affected, important for the nation building force. We conclude that hand injuries are a real burden to society and are worthwhile to be prevented with special attention in this industrial sector for occupational accidents. By this we can suggest that the prospective study with proper follow up should be performed to know the residual effect of the hand injuries as it is more disabling later due to lack of good rehabilitative measures, along with economic loss to the families, societies and consequently to the nation.

\section{References}

1. Larsen CF, Mulder S, Johansen AM, Stam C. The epidemiology of hand injuries in The Netherlands and Denmark. Eur J Epidemiol. 2004; 19(4):323-7.
2. Angermann $P$, Lohmann $M$. Injuries to the hand and wrist. A study of 50,272 injuries. J Hand Surg [Br]. 1993; 18(5):642-4.

3. Skov O, Jeune B, Lauritsen JM, Barfred T. Occupational hand injuries. A population-based description of the incidence and referral to casualty departments. Ugeskr Laeger. 1999; 31;161(22):3285-8

4. Hansen TB, Carstensen O. Hand injuries in agricultural accidents. $\mathrm{J}$ Hand Surg [Br]. 1999; 24(2):190-2.

5. Packer GJ, Shaheen MA. Patterns of hand fractures and dislocations in a district general hospital $\mathrm{J}$ Hand Surg [Br]. 1993; 18(4):511-4.

6. Skov $\mathrm{O}$. The incidence of hospitaltreated occupational hand injuries. J Hand Surg [Br]. 1994; 19(1):118-9.

7. Van Onselen EB, Karim RB, Hage JJ, Ritt MJ. Prevalence and distribution of hand fractures. J Hand Surg [Br]. 2003; 28(5):491-5.

8. Hove LM. Fractures of the hand. Distribution and relative incidence. Scand J Plast Reconstr Surg Hand Surg. 1993; 27(4):317-9.

9. Broback LG, Ekdahl PH, Aschan GW, Grenabo JK. Clinical and socioeconomical aspects of hand injuries. Acta Chir Scand. 1978; 144(7-8):45561. 
10. Rosberg HE, Dahlin LB. Epidemiology of hand injuries in a middle-sized city in southern Sweden: a retrospective comparison of 1989 and 1997. Scand J Plast Reconstr Surg Hand Surg. 2004; 38(6):347-55.
11. J. Boyd, M. Hill, J. Pollock, G. Casey, K. Gelberg, S. Roerig, A. Grant. Epidemiological Characteristics of Reported Hand Injuries- New York State 1991-1995. Journal of Agricultural Safety and Health 3(2):101. @1997. 